\title{
Glassy dynamics of two poly(ethylene glycol) derivatives in the bulk and in nanometric confinement as reflected in its inter- and intra-molecular interactions
}

Cite as: J. Chem. Phys. 149, 064501 (2018); https://doi.org/10.1063/1.5039518

Submitted: 08 May 2018 . Accepted: 24 July 2018 . Published Online: 09 August 2018

Małgorzata Jasiurkowska-Delaporte, Wilhelm Kossack (D), Wycliffe K. Kipnusu (D), Joshua R. Sangoro (iD, Ciprian lacob, and Friedrich Kremer
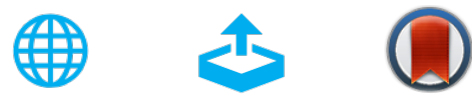

View Online

Export Citation

\section{ARTICLES YOU MAY BE INTERESTED IN}

Glassy dynamics of polymethylphenylsiloxane in one- and two-dimensional nanometric confinement-A comparison

The Journal of Chemical Physics 146, 203302 (2017); https://doi.org/10.1063/1.4974767

Communication: Correlation of terminal relaxation rate and viscosity enhancement in supramolecular small-molecule liquids

The Journal of Chemical Physics 148, 221102 (2018); https://doi.org/10.1063/1.5037803

Comparison of single particle dynamics at the center and on the surface of equilibrium glassy films

The Journal of Chemical Physics 149, 074501 (2018); https://doi.org/10.1063/1.5039505 


\title{
Glassy dynamics of two poly(ethylene glycol) derivatives in the bulk and in nanometric confinement as reflected in its inter- and intra-molecular interactions
}

\author{
Małgorzata Jasiurkowska-Delaporte, ${ }^{1, a)}$ Wilhelm Kossack, ${ }^{2}$ Wycliffe K. Kipnusu, ${ }^{3}$ \\ Joshua R. Sangoro, ${ }^{4}$ Ciprian lacob, ${ }^{5,6}$ and Friedrich Kremer $^{2}$ \\ ${ }^{1}$ The Henryk Niewodniczański Institute of Nuclear Physics, Polish Academy of Sciences, \\ Radzikowskiego 152, 31-342 Kraków, Poland \\ ${ }^{2}$ Institute of Experimental Physics I, University of Leipzig, Linnéstr. 5, Leipzig, Germany \\ ${ }^{3}$ GROC.UJI, Institute of New Imaging Technologies, Universitat Jaume I, Avda. Sos Baynat s/n, \\ 12071 Castellón, Spain \\ ${ }^{4}$ Department of Chemical and Biomolecular Engineering, University of Tennessee, Knoxville, \\ Tennessee 37996, USA \\ ${ }^{5}$ Department of Materials Science and Engineering, Penn State University, University Park, \\ Pennsylvania 16802, USA \\ ${ }^{6}$ National Research and Development Institute for Cryogenic and Isotopic Technologies, ICSI, \\ 240050 Râmnicu Valcea, Romania
}

(Received 8 May 2018; accepted 24 July 2018; published online 9 August 2018)

\begin{abstract}
The inter- and intra-molecular interactions as they evolve in the course of glassy solidification are studied by broadband dielectric — and Fourier-transform infrared - spectroscopy for oligomeric derivatives of poly(ethylene glycol) derivatives, namely, poly(ethylene glycol) phenyl ether acrylate and poly(ethylene glycol) dibenzoate in the bulk and under confinement in nanoporous silica having mean pore diameters 4,6 , and $8 \mathrm{~nm}$, with native and silanized inner surfaces. Analyzing the spectral positions and the oscillator strengths of specific IR absorption bands and their temperature dependencies enables one to trace the changes in the intra-molecular potentials and to compare it with the dielectrically determined primarily inter-molecular dynamics. Special emphasis is given to the calorimetric glass transition temperature $\mathrm{T}_{\mathrm{g}}$ and $\mathrm{T}_{\alpha \beta} \approx 1.25 \mathrm{~T}_{\mathrm{g}}$, where characteristic changes in conformation appear, and the secondary $\beta$-relaxation merges with the dynamic glass transition ( $\alpha$-relaxation). Furthermore, the impact of main chain conformations, inter- and intra-molecular hydrogen bonding, and nanometric confinement on the dynamic glass transition is unraveled. Published by AIP Publishing. https://doi.org/10.1063/1.5039518
\end{abstract}

\section{INTRODUCTION}

Due to their unique properties, glasses are attractive for various applications in modern technology ${ }^{1,2}$ such as optical fibers or glass ceramic. The glass transition also plays an essential role in the pharmaceutical sector, ${ }^{3}$ food preservation, ${ }^{4}$ and polymer industry. ${ }^{5}$ In general, a glass is defined as a disordered material that lacks crystalline order but has macroscopic properties of a solid. ${ }^{6}$ For a large group of organic ${ }^{7,8}$ and inorganic systems, ${ }^{9-12}$ a vitreous state is obtained by cooling rapidly enough to avoid crystallization. The transformation from liquid to a non-equilibrium glassy state is indicated by a continuous step in heat capacity, resembling the second-order thermodynamic-transition. ${ }^{13}$ However, it is not truly thermodynamic transition, but it is a kinetic phenomenon. The unique feature of glass-forming systems upon cooling is dramatic slowing down of a structural $\alpha$-relaxation on approaching the glass transition temperature $T_{g}$, along with $\beta$-relaxation that persists at temperatures below $\mathrm{T}_{\mathrm{g}}{ }^{14}$ The origin of secondary relaxations and their relationship with the structural $\alpha$-relaxation has been a subject of intense debate. ${ }^{15-21}$

a)Malgorzata.Jasiurkowska-Delaporte@ifj.edu.pl
Despite extensive studies, our understanding of the origin of the glass transition and the drastic slowing down of molecular dynamics on approaching the calorimetric glass transition temperature is still an actual problem of condensed matter physics. ${ }^{1,2,6}$ Several theoretical approaches including the Adam-Gibbs theory, ${ }^{22,23}$ mode coupling theory, ${ }^{24}$ free volume theory, ${ }^{25}$ three dimensional energy landscape model, ${ }^{26}$ or random first-order transition theory ${ }^{27}$ do not provide a consistent picture of the glass transition phenomenology. According to the Adam-Gibbs theory, the non-exponential temperature dependence of the $\alpha$-relaxation is attributed to cooperativity of fluctuating molecules. A weakness of these approaches is the fact that they consider molecules as hard spheres and thus neglect intramolecular forces. Bahar et al. ${ }^{28}$ suggested that beside intermolecular correlations, intramolecular interactions influence supercooled state dynamics. The significance of the contribution of intramolecular interaction to dynamic glass transition has been recently proven by a combination of Broadband Dielectric Spectroscopy (BDS) and Fourier-Transform Infrared (FTIR) spectroscopy. ${ }^{29-31}$ This approach has been employed to study liquid crystals under confinement, ${ }^{32}$ glass transition of low molecular weight, $, 29,30,33$ and polymeric systems ${ }^{30,34}$ in bulk. It has been reported that various 
molecular units are influenced differently by the vitrification process.

Particularly intriguing for both fundamental and practical uses is a phenomenon of the glass transition in restricted geometry. ${ }^{35}$ The effect of nanopores on molecular dynamics is usually demonstrated as (i) the deviation of structural relaxation from the Vogel-Fulcher-Tammann (VFT) on approaching the $T_{g}$, (ii) existence of the slow, additional dynamics processes interpreted as resulting from molecular interaction with the pore walls, and (iii) depression of $\mathrm{T}_{\mathrm{g}}$. Recently, Kipnusu et al. ${ }^{36,37}$ have demonstrated by a combination of broadband dielectric spectroscopy and positron annihilation lifetime spectroscopy that enhancement of molecular mobility on approaching $\mathrm{T}_{\mathrm{g}}$ with decreasing pores size is related to the reduction in molecular packing density in a constrained environment. Another recent study described the effect of negative pressure on dynamics in nanopores,${ }^{38}$ and another study noted that vitrification of molecular fraction in the immediate vicinity of the pore walls is slower than those located in the centre. ${ }^{39}$ Alexandris et al. ${ }^{40}$ have found that there is a trend of decreasing glass temperature with increasing interfacial energy for polymers/oligomers in nanopores. However, few, if any, reports describe the impact of confinement on intra-molecular dynamics.

In the current contribution, we report the influence of pore size on dynamics of two molecular systems of comparable molecular weight and calorimetric glass transition temperature of poly(ethylene glycol) phenyl ether acrylate (PEGPEA) and poly(ethylene glycol) dibenzoate (PEGD). This choice of materials allows us to study the impact of different end groups, i.e., phenyl rings or acrylates on the dynamics of the ethylene glycol chain. The silica membranes with unidirectional nano-pores of well-defined diameters provide an ideal nanoscale system to explore molecular mobility under confinement. The motivation of this study is to provide a microscopic description of the impact of geometrical restriction on inter- and intramolecular dynamics on approaching the $T_{g}$ which could lead to a universal picture of molecular dynamics under confinement.

\section{EXPERIMENTAL DETAILS}

Poly(ethylene glycol) phenyl ether acrylate (PEGPEA) $\mathrm{M}_{\mathrm{n}} \sim 324 \mathrm{Da}$ (4 repeat units) and poly(ethylene glycol) dibenzoate (PEGD) $\mathrm{M}_{\mathrm{n}} \sim 410 \mathrm{Da}$ (5 repeat units) were purchased from Sigma Aldrich and used as received. Porous silica membranes were prepared by electrochemical etching of highly doped (p-type, $\langle 100\rangle$ ) silicon wafers and subsequent oxidation. The obtained unidirectional and non-intersecting nano-pores are oriented along the membrane's surface normal and exhibit average diameters of $4 \mathrm{~nm}, 6 \mathrm{~nm}$, or $8 \mathrm{~nm}$. Details of preparation and characterization can be found in Refs. 37 and 41. Prior to the measurements, the silicon membranes were annealed in a vacuum chamber $\left(10^{-6} \mathrm{mbar}\right)$ at $573 \mathrm{~K}$ and then filled with the mentioned materials by capillary effects. To study the interactions of the poresurface with the guest molecules, the inner surfaces of the porous membranes were coated using hexamethyldisilazane in 2 samples. By this procedure, the silanol groups on the pore-surface were replaced with hydrophobic trimethylsilyl groups. $^{42}$

Broadband dielectric measurements were performed using a Novocontrol High Resolution Alpha Dielectric Analyzer $(0.1 \mathrm{mHz}-10 \mathrm{MHz})$ and an HP impedance analyzer $(1 \mathrm{MHz}-1.8 \mathrm{GHz})$ in the temperature range $323 \mathrm{~K}-143 \mathrm{~K}$, stabilized with accuracy better than $0.1 \mathrm{~K}$ by Quattro temperature controllers using pure nitrogen gas as the heating agent. The relaxation rates were determined by fitting the complex dielectric spectra with an empirical Havriliak-Negami function given by ${ }^{8}$

$$
\varepsilon_{H N}^{*}(\omega)=\varepsilon^{\prime}(\omega)-i \varepsilon(\omega)=\varepsilon_{\infty}+\frac{\Delta \varepsilon}{\left[\left(1+\left(i \omega \tau_{H N}\right)^{\beta}\right)\right]^{\gamma}}+\frac{\sigma_{0}}{i \omega \varepsilon_{0}},
$$

where $\varepsilon^{\prime}$ and $\varepsilon^{\prime \prime}$ are the real and imaginary parts of the complex dielectric function, $\Delta \varepsilon$ is the dielectric strength which is proportional to the number density of the fluctuating dipolar units, $\tau_{H N}$ denotes the relaxation time, $\beta$, and $\gamma$ are the shape parameters, and $\sigma_{0}$ is the dc-conductivity.

To obtain the effective dielectric strength for confined molecules, a model of two impedances in parallel was employed as described in detail elsewhere. ${ }^{31}$

Fourier transform infrared (FTIR) absorption measurements were carried out using a Bio-Rad FTS 6000 spectrometer from $700 \mathrm{~cm}^{-1}$ to $5000 \mathrm{~cm}^{-1}$ with a resolution of $2 \mathrm{~cm}^{-1}$. The temperature was controlled with an uncertainty of less than $0.5 \mathrm{~K}$ by means of a Linkam THMS 600 cell equipped with ZnSe windows. The IR spectra were measured upon cooling and subsequent heating in the same temperature range as dielectric measurements. The absorption bands discussed in the text were fitted using a sum of Gaussian functions after subtraction of a tangential baseline. ${ }^{43}$ The shift of bands for each sample was determined with respect to their peak position at the starting temperature $(323 \mathrm{~K})$. The corresponding oscillator strength $(f(\mathrm{~T}))$ which is directly related to the integrated absorbance ${ }^{44}$ was also rescaled with respect to the value at $323 \mathrm{~K}(f(323 \mathrm{~K}))$ as follows:

$$
f_{r}(\mathrm{~T})=\frac{f(\mathrm{~T})}{f(323 \mathrm{~K})},
$$

where $f_{r}$ is the rescaled value.

\section{RESULTS AND DISCUSSION}

Infrared spectroscopy gives the unique opportunity to examine the impact of the glass transition and the geometrical confinement on intra-molecular dynamics. Comparison of the IR absorption spectra of bulk and confined PEGEA and PEGD reveals the strong influence of the end groups on the vibrational dynamics of oxyethylene chains (Fig. 1). The IR spectra of PEGEA show absorption bands specific to gaucheconformations around $\mathrm{CH}_{2}-\mathrm{CH}_{2}$ bonds: (i) the simultaneous appearance of $\mathrm{CH}_{2}$ wagging $\tau\left(\mathrm{CH}_{2}\right)$ at $1350 \mathrm{~cm}^{-1}$ and twisting mode $\tau\left(\mathrm{CH}_{2}\right)$ at $1244 \mathrm{~cm}^{-1}$, ${ }^{45}$ and (ii) a coupled mode of $\mathrm{CH}_{2}$ wagging and $\mathrm{CH}_{2}$ twisting at $1415 \mathrm{~cm}^{-1} .{ }^{46}$ The double absorption band with the maxima at $1136 \mathrm{~cm}^{-1}$ and $1106 \mathrm{~cm}^{-1}$ corresponds to the stretching vibration of COC units in gaucheconfiguration and trans-configuration, respectively. ${ }^{47,48}$ Upon cooling, the trans-content increases from $36 \% \pm 5 \%$ to 


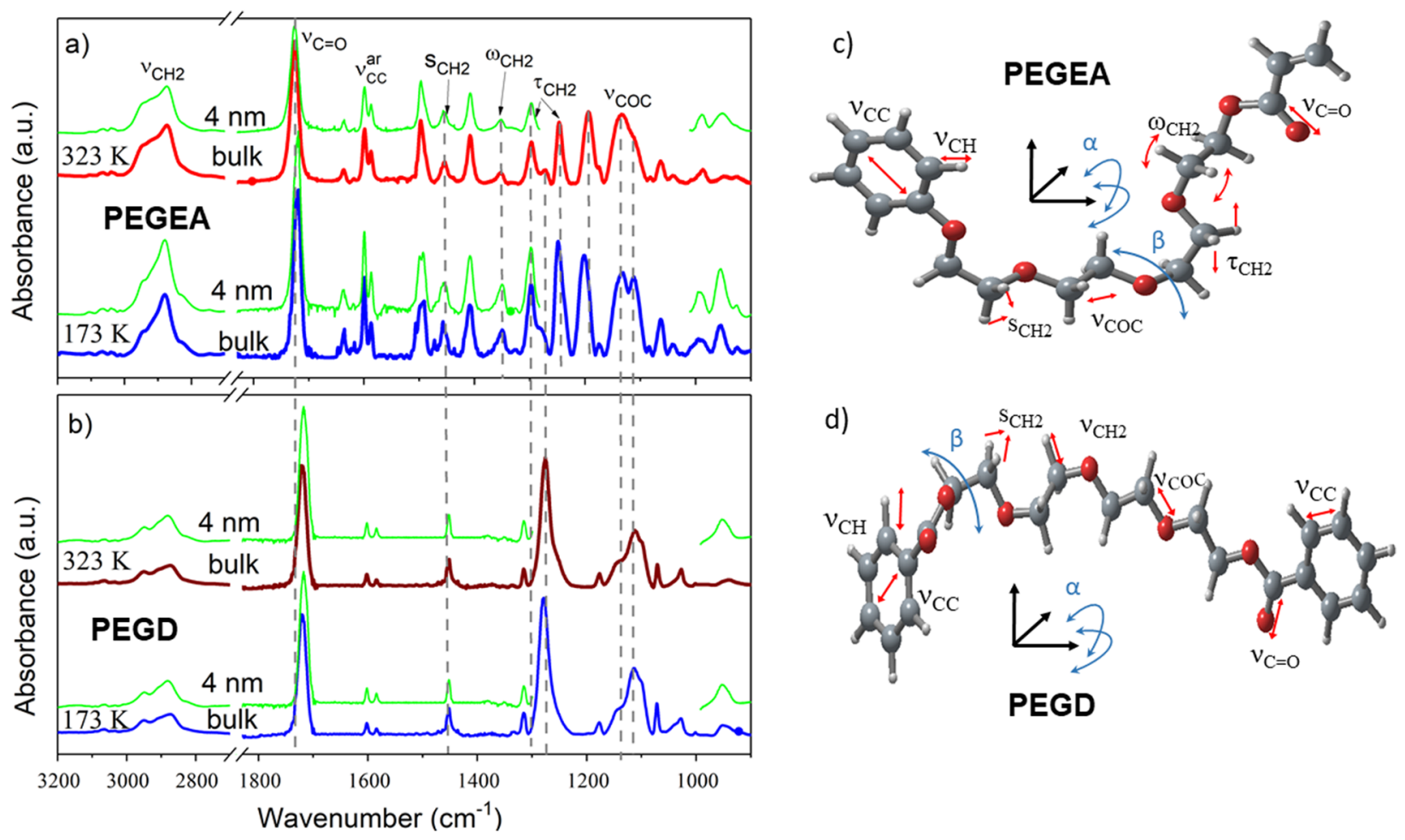

FIG. 1. Infrared absorption spectra as measured for (a) PEGPEA and (b) PEGD at $323 \mathrm{~K}$ and $173 \mathrm{~K}$ in bulk and 4 nm pores. The symbols denote the following: $v_{\mathrm{C}=\mathrm{O}}-\mathrm{C}=\mathrm{O}$ stretching, $v_{C C}^{a r}-\mathrm{CC}$ stretching of the aromatic rings, $\omega_{\mathrm{CH}_{2}}-$ wagging vibration of $\mathrm{CH}_{2}, \tau_{\mathrm{CH}_{2}}-\mathrm{CH}_{2}$ twisting, $\mathrm{s}_{\mathrm{CH}_{2}}-\mathrm{CH}_{2}$ scissoring, $v_{\mathrm{COC}}-$ stretching of $\mathrm{COC}$ units in combination with $\mathrm{C}-\mathrm{C}$ stretching and $\mathrm{CH}_{2}$ rocking. (c) and (d) show the structure of PEGEA and PEGD with the assignment of $\alpha$ and $\beta$ relaxations and IR vibrations as indicated. Geometry of the lowest energy conformation of the molecule optimized by a quantum mechanical method [density functional theory (DFT) at the B3LYP/6-31 level]. The spectra were normalized with respect to the area of the $\mathrm{CH}_{2}$ vibration band at $2880 \mathrm{~cm}^{-1}$ at $323 \mathrm{~K}$.

about $47 \%$ in the vicinity of the $\mathrm{T}_{\mathrm{g}}$ at the expense of gauche-conformers (see below). The conformational energy difference between both configurations obtained on the basis of the van't Hoff analysis ${ }^{49,50}$ is $10 \pm 4 \mathrm{~kJ} / \mathrm{mol}$. For PEGD, the strong COC vibration bands at $1111 \mathrm{~cm}^{-1}$ and the comparably far weaker band at $1142 \mathrm{~cm}^{-1}$ indicate predominant transconformations of the repeat units. The relative weight of these two bands changes only slightly, indicating only small changes $(<5 \%)$ of the trans-gauche-composition and complicating a van't Hoff analysis. Further proof for the higher abundance of trans-units in PEGD is also found by the low intensity of vibrational bands around $1244 \mathrm{~cm}^{-1}$ and $1350 \mathrm{~cm}^{-1}$ and the strong absorption around $1279 \mathrm{~cm}^{-1}$. 51,52 The vibrational dynamics of the end groups is reflected in the double absorption bands at around $1600 \mathrm{~cm}^{-1}$ corresponding to $\mathrm{C}=\mathrm{C}$ vibrations of phenyl rings and the stretching vibration band of the polar $\mathrm{C}=\mathrm{O}$ group $\left(v_{\mathrm{C}=0}\right)\left[\sim 1725 \mathrm{~cm}^{-1}\right.$ (PEGEA) and $\sim 1720 \mathrm{~cm}^{-1}$ (PEGD) at $323 \mathrm{~K}]$. In nanopores, the position of the $v_{\mathrm{C}=\mathrm{O}}$ peak is red shifted with respect to bulk due to the increased free molecular volume. The temperature impact on dynamics of the end groups will be discussed in detail in the next paragraphs.

Figure 2 compares the selected vibrational bands in bulk and in nanopores. The band related to the scissoring vibration of $\mathrm{CH}_{2}$ groups occurs in the wavenumber range 1475$1445 \mathrm{~cm}^{-1}$ [Figs. 3(a) and 3(b)]. In the PEGEA bulk at $323 \mathrm{~K}$, three bands show up: $\mathrm{s}_{\mathrm{CH}_{2}}, \mathrm{~s}^{\prime} \mathrm{CH}_{2}$, and $\mathrm{s}^{\mathrm{t}} \mathrm{CH}_{2}$, respectively, at $1453 \mathrm{~cm}^{-1}, 1457 \mathrm{~cm}^{-1}$, and $1471 \mathrm{~cm}^{-1}$. All bands correspond to scissoring vibrations of the $\mathrm{CH}_{2}$ units in the
PEG backbone. The $\mathrm{s}^{\mathrm{t}} \mathrm{CH}_{2}$ vibration is assigned to consecutive trans-segments, whereas for the other two bands no conformational specificity is known. ${ }^{53}$ As the temperature decreases, the trans-specific absorption grows by a factor of $\sim 2$, accompanied by a moderate increase of $<30 \%$ for $\mathrm{s}_{\mathrm{CH}_{2}}$ and $\mathrm{s}^{\prime} \mathrm{CH}_{2}$. Interestingly, under confinement of $4 \mathrm{~nm}$ pores, $\mathrm{s}^{\mathrm{t}} \mathrm{CH}_{2}$ in PEGEA increases even by a factor of 4 , whereas the absorption of $\mathrm{s}_{\mathrm{CH}_{2}}$ and $\mathrm{s}^{\prime} \mathrm{CH}_{2}$ approximately doubles. In contrast to that, no significant confinement effects are observed for PEGD.

The bands between $960 \mathrm{~cm}^{-1}$ and $915 \mathrm{~cm}^{-1}$ originate from conformationally sensitive modes, with contributions from $\mathrm{CH}_{2}$-rocking $\left(\rho_{\mathrm{CH}_{2}}\right)$ as well as $\mathrm{C}-\mathrm{O}-\left(v_{\mathrm{CO}}\right)$ and $\mathrm{C}-\mathrm{C}$ stretching $\left(v_{\mathrm{CC}}\right)$ in the PEG backbone (Fig. 2) ${ }^{53,54}$ Vibrations between $955 \mathrm{~cm}^{-1}$ and $935 \mathrm{~cm}^{-1}$ should correspond to consecutive $\mathrm{C}-\mathrm{C}$ units in trans-form independent of the conformation of the interstitial $\mathrm{C}-\mathrm{O}$ moieties. However, in this region, there are also vibrations reported to originate from $\mathrm{C}-\mathrm{C}$ groups in gauche-form. ${ }^{53}$ In the range between $925 \mathrm{~cm}^{-1}$ and $910 \mathrm{~cm}^{-1}$, the theoretical calculation predicts the vibration corresponding to $\mathrm{C}-\mathrm{C}$ units in gauche-conformation with $\mathrm{C}-\mathrm{O}$ moieties in mixed trans-and gauche-states in between. ${ }^{53}$ For PEGEA in bulk, a peak at $927 \mathrm{~cm}^{-1}$ and a broad, possibly double-band around $950 \mathrm{~cm}^{-1}$ are observed at $323 \mathrm{~K}$. The latter shifts strongly to about $955 \mathrm{~cm}^{-1}$ upon cooling. In bulk PEGD, the IR band is composed of three peaks with the centers at $925 \mathrm{~cm}^{-1}, 940 \mathrm{~cm}^{-1}$, and $951 \mathrm{~cm}^{-1}$. Unfortunately, decomposition and assignment suffer from some 

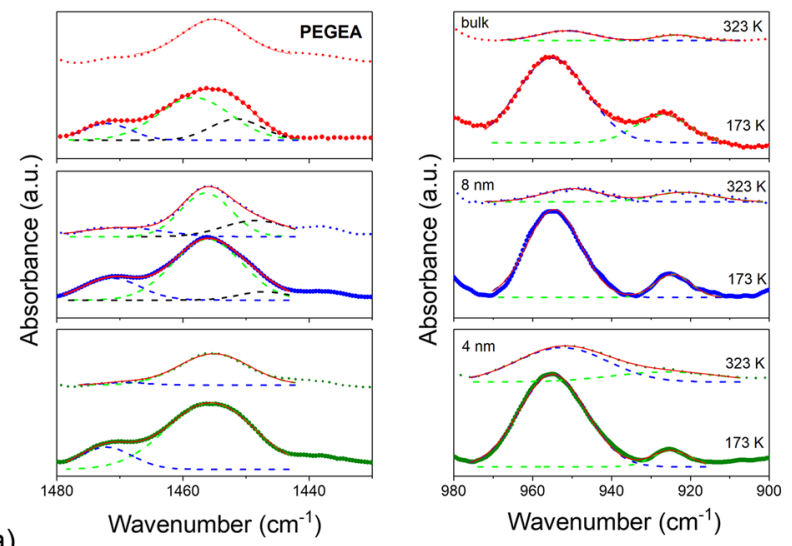

a)
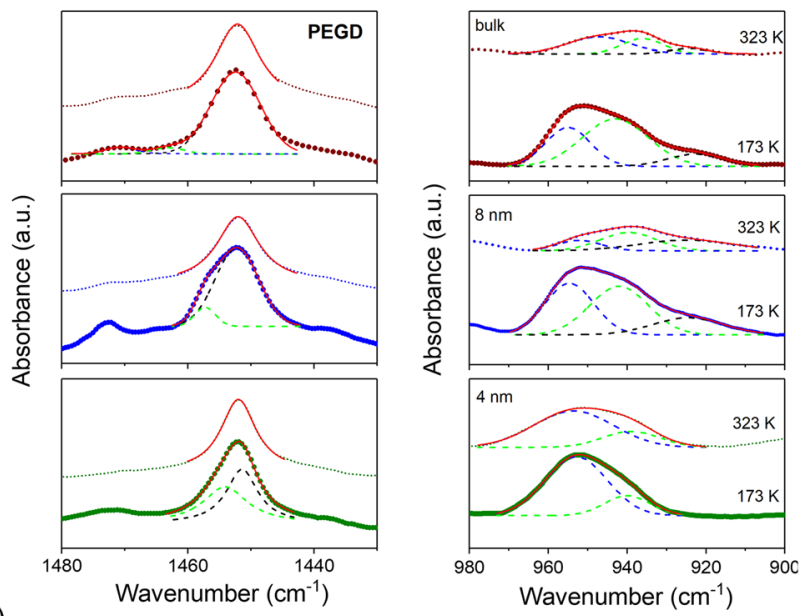

b)

FIG. 2. Enlarged IR-absorption bands of the scissoring vibration of $\mathrm{CH}_{2}$ $\left(\mathrm{s}_{\mathrm{CH}_{2}}\right)$ in the wavenumber range $1475-1430 \mathrm{~cm}^{-1}$ and the $\mathrm{CO}$ stretching $\left(v_{\mathrm{CO}}\right)$ and $\mathrm{CH}_{2}$ rocking $\left(\rho_{\mathrm{CH}_{2}}\right)$ in the range $980-900 \mathrm{~cm}^{-1}$ for PEGEA (a) and PEGD (b) in bulk and in nanopores as indicated. The spectra were normalized with respect to the $\mathrm{CH}_{2}$ vibration band at $2880 \mathrm{~cm}^{-1}$.

ambiguities. Nevertheless, for higher wavenumbers, absorption peaks predominantly arise from trans-conformations, whereas below $930 \mathrm{~cm}^{-1}$, gauche-conformers dominate. For PEGEA, the relative increase of the absorption in the trans-dominated region upon cooling is by a factor of 3 to 4 larger than around $925 \mathrm{~cm}^{-1}$. This redistribution of absorbance illustrates the increasing fraction of trans-conformers. In $4 \mathrm{~nm}$ pores at high $\mathrm{T}(323 \mathrm{~K})$, the absorption around $955 \mathrm{~cm}^{-1}$ is more than 3 times as high as in $8 \mathrm{~nm}$ or bulk, proving a larger preference of trans-conformations under nanometric $^{47}$ confinement. For PEGD, the observed effects are qualitatively the same, only weaker by about a factor of more than 2.

The dielectric loss $\varepsilon^{\prime \prime}(\mathrm{f})$ spectra of PEGEA and PEGD in bulk and in native and silanized pores of mean diameter $4 \mathrm{~nm}$ are shown in Fig. 3. Two relaxation processes, $\alpha$ and $\beta$ process, are observed for the bulk sample and the one confined in treated pores. An additional process slower than $\alpha$-relaxation is found in native pores, and it is attributed to the layer of partially immobilized molecules on the pore walls. ${ }^{36,55}$ This process is not detected in pores after silanization. The existence of the surface layer in silica pores has also been predicted for confined ethylene glycol by molecular dynamics simulations ${ }^{56}$ and proposed by Raman studies. ${ }^{47}$ The temperature dependencies of the $\alpha$ relaxation rates for the sample in the bulk state [see Figs. 4(a) and 5(a)] are well described by the Vogel-FulcherTammann equation given as $\omega_{\alpha}=\omega_{\infty} \exp \left(\frac{-D T_{0}}{T-T_{0}}\right)$, where $\omega_{\infty}$ describes the high frequency limit, $\mathrm{D}$ is a fragility parameter, and $\mathrm{T}_{0}$ is the Vogel temperature. ${ }^{8}$ For PEGPA and PEGD confined in nanopores, an enhancement of molecular dynamics is observed on approaching $\mathrm{T}_{\mathrm{g}}$. Deviation of $\omega_{\alpha}(T)$ from VFT dependencies is more pronounced as the mean diameter of pores decreases (Figs. 6 and 7). This effect that is commonly observed for confined liquids is attributed to the increasing free volumes of confined molecules with decreasing pore sizes. ${ }^{36,57}$ The $\beta$-relaxation process is related to the local motions in oxyethylene chains. ${ }^{58}$ The relaxation rates $\omega_{\beta}$ of the $\beta$-process are not influenced by nanopores. The temperature dependence of $\omega_{\beta}$ shows an Arrhenius-type of thermal activation with activation energies $\left(E_{a}\right)$ of $32 \pm 2 \mathrm{~kJ} / \mathrm{mol}$ and $34 \pm 2 \mathrm{~kJ} / \mathrm{mol}$ for PEGEA and PEGD (Table I and Figs. 4-7), respectively. These values of $E_{a}$ coincide with the results obtained for polyethylene glycols with comparable chain length. ${ }^{58}$
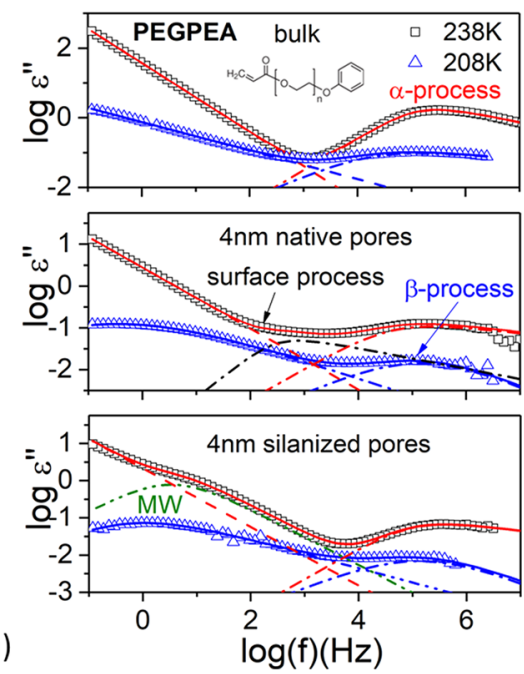
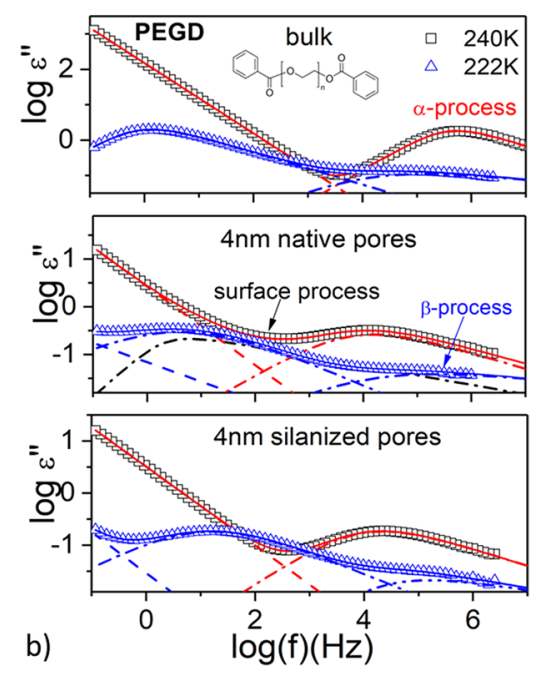

FIG. 3. Dielectric loss spectra of (a) PEGPEA at $238 \mathrm{~K}$ and $208 \mathrm{~K}$ and (b) PEGD at $240 \mathrm{~K}$ and $222 \mathrm{~K}$ as indicated for bulk and confined in $4 \mathrm{~nm}$ native silica pores and $4 \mathrm{~nm}$ silanized pores. The lines indicate fits to the data according to the HavriliakNegami functions. The dashed-dotted and dashed lines correspond to contributions from different dielectric processes and conductivity contribution, respectively. MW is a process caused by Maxwell-Wagner-polarization (dasheddotted-dotted line). 


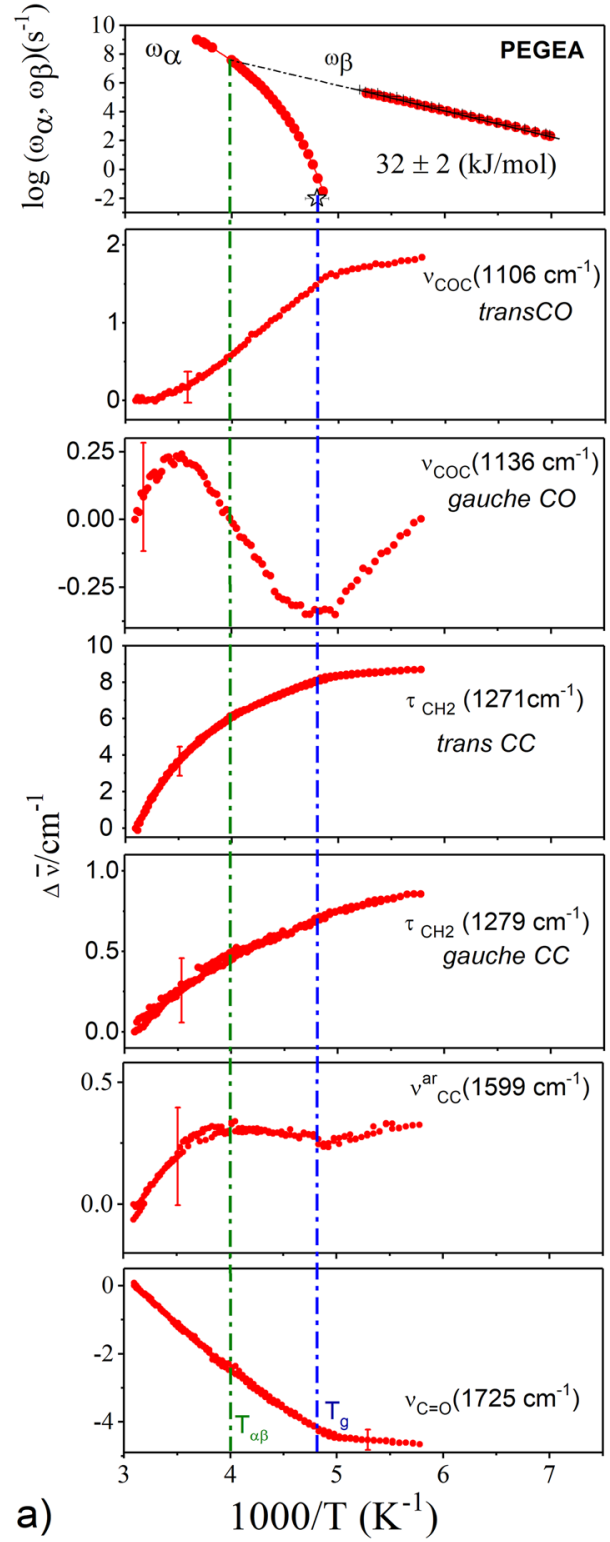

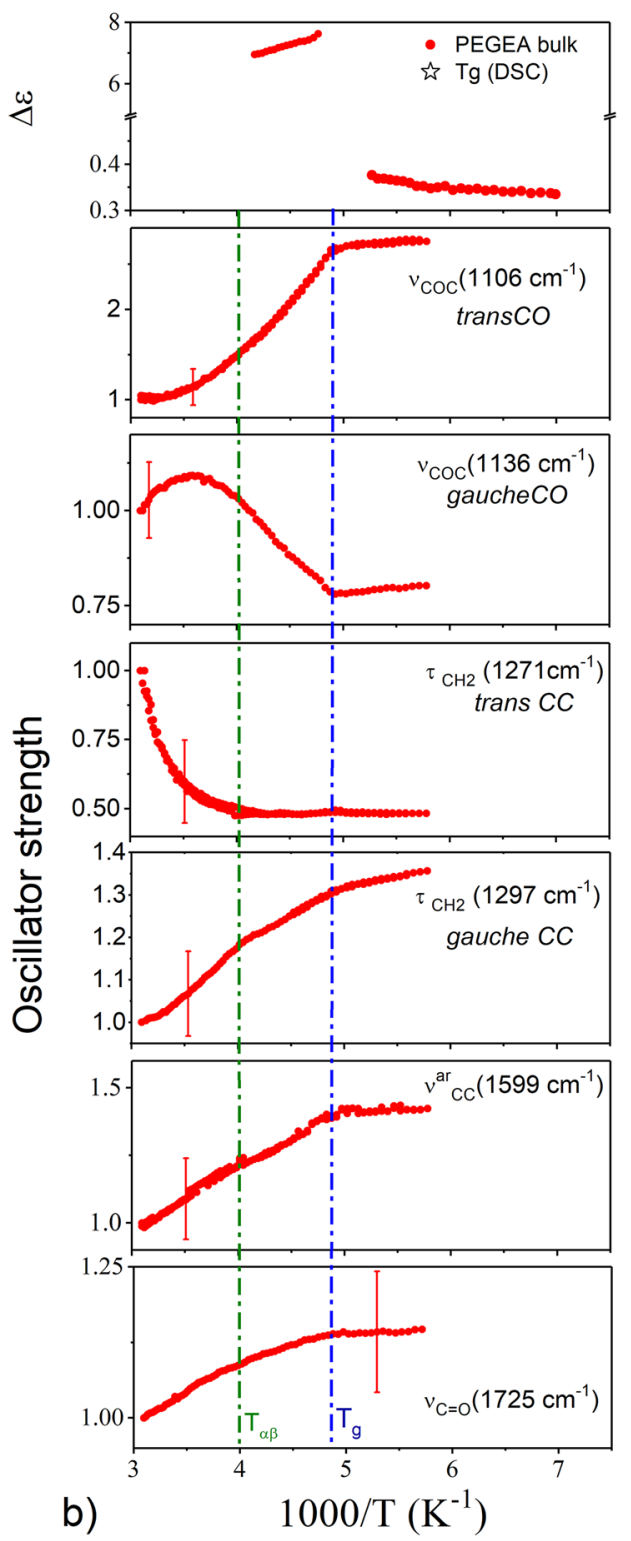

FIG. 4. Comparison of inter- and intramolecular dynamic of PEGEA in bulk. (a) Dynamic glass transition $(\alpha-$ relaxation) and the local ( $\beta$ ) processes and the shift of selected absorption bands (stretching of COC: $v_{\mathrm{COC}}$, stretching of CC aromatic: $v_{\mathrm{CC}}$, stretching of $\left.\mathrm{C}=\mathrm{O}: v_{\mathrm{C}=\mathrm{O}}\right) \Delta \bar{v}=\bar{v}-\bar{v}_{323 \mathrm{~K}}$ of PEGEA with respect to the spectral position at $323 \mathrm{~K}$. (b) The dielectric strength $(\Delta \varepsilon)$ and the oscillator strength rescaled with respect to the value at $323 \mathrm{~K}$. The vertical dashed-dotted and dashed lines denote $\mathrm{T}_{\alpha \beta}$ and the calorimetrically determined $\mathrm{T}_{\mathrm{g}}$. The error bars are smaller than the symbols if not stated otherwise.
Figures 4(a) and 5(a) present the inter- and intramolecular dynamics in terms of the relaxation rates and the band shifts for PEGEA and PEGD in bulk, as measured by BDS and IR, respectively. Similarly, the dielectric strength is juxtaposed with the corresponding oscillator strength, which is proportional to the integrated absorbance obtained by fitting the absorption peak, as described in Sec. II [Figs. 4(b) and 5(b)]. The IR bands show their own signature with the decreasing temperature: (i) The stretching vibrations of COC units $\left(v_{\text {COC }}\right)$ in trans $\left(\sim 1106 \mathrm{~cm}^{-1}\right.$ for PEGEA and $\sim 1111 \mathrm{~cm}^{-1}$ for PEGD) show shifts of about $2 \mathrm{~cm}^{-1}$ above $T_{g}$. (ii) The absorption peak corresponding to vibrations of COC moieties in gauche-conformations $\left(\sim 1136 \mathrm{~cm}^{-1}\right.$ for PEGEA and $1142 \mathrm{~cm}^{-1}$ for PEGD) is blue shifted by about the same amplitude. Unfortunately, these bands overlap with each other and further neighbouring bands, complicating unanimous determination of their spectral position. For PEGEA, the related oscillator strengths change about $40 \%$ between $\mathrm{T}_{\alpha \beta} \approx 250 \mathrm{~K}$ and $T_{g}$, whereas smaller changes are found at higher temperatures and below $T_{g}$ (Fig. 4). The vibrations related to PEGD gauche-conformation also show a characteristic change of its oscillator strength at $\mathrm{T}_{\alpha \beta} \approx 260 \mathrm{~K}$ and at $\mathrm{T}_{\mathrm{g}}$ (Fig. 5). The temperature evolution of the oscillator strength indicates that upon cooling high energy (gauche) forms start to transform to low energy conformers (trans) above $\mathrm{T}_{\alpha \beta}$. (iii) The temperature dependence of the band shift of $v^{\mathrm{ar}}(\mathrm{CC})$ shows two "kinks": one at the $\mathrm{T}_{\mathrm{g}}$ temperature and the other one coincides with extrapolated merging temperature of the $\alpha$ and $\beta$ relaxations $\left(\mathrm{T}_{\alpha \beta}\right)$. Although indicated systematic uncertainties for the oscillator strength and spectral position are large, the observed characteristic changes are well reproducible and do not show significant scatter. (iv) The stretching vibration band of the strongly polar $\mathrm{C}=\mathrm{O}$ group $\left(v_{\mathrm{C}=\mathrm{O}}\right)\left[\sim 1725 \mathrm{~cm}^{-1}\right.$ (PEGEA) and $\sim 1720 \mathrm{~cm}^{-1}$ (PEGD) at $323 \mathrm{~K}$ ] shows a red shift with a change of slope at $T_{g}$ below which very weak temperature dependence is observed. This can be explained by the thermal contraction of the sample which causes an increase in attractive electrostatic, and $\mathrm{H}$-bonding interactions of the carbonyl groups with neighbouring molecules and consequently leads to a red shift. ${ }^{59,60}$ The band shift is more pronounced 

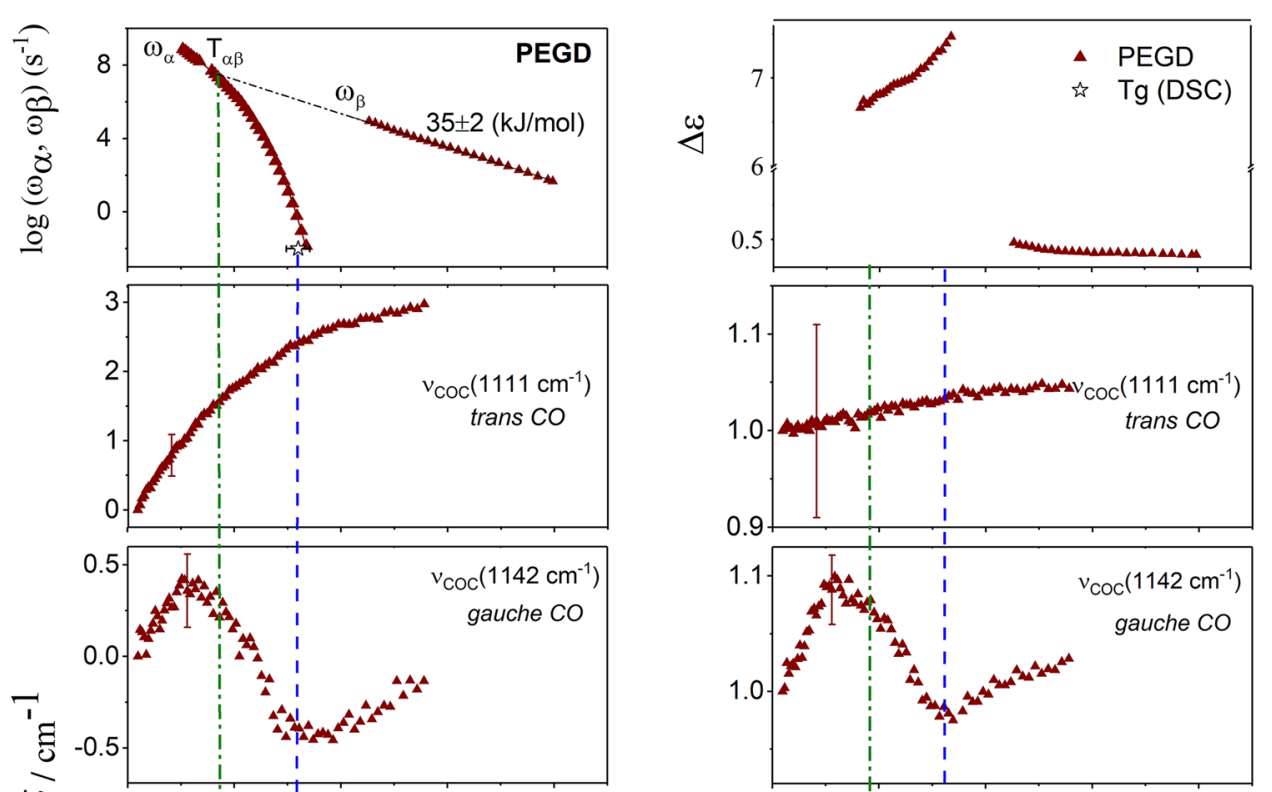

$1>$
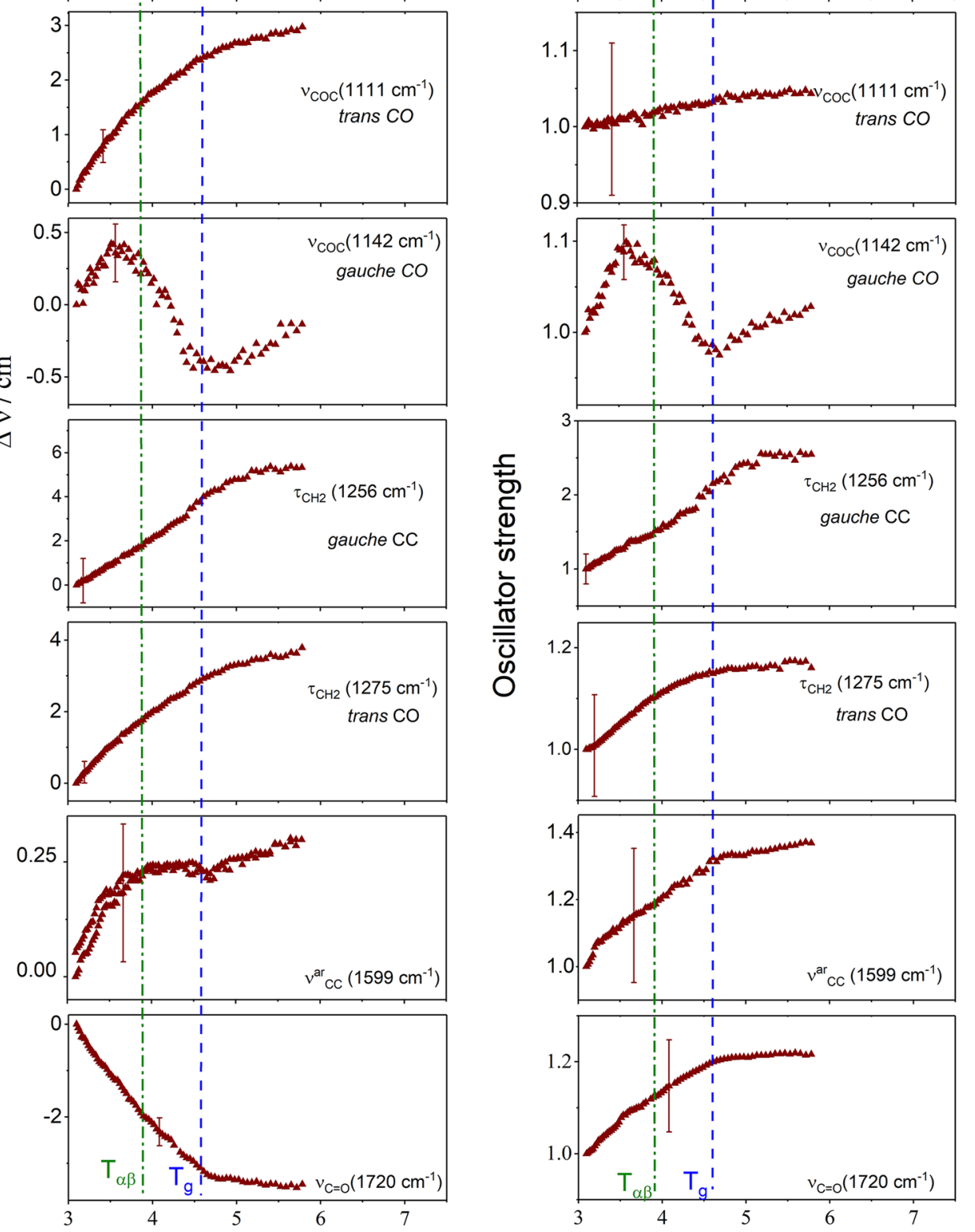

a)

$1000 / \mathrm{T}\left(\mathrm{K}^{-1}\right)$

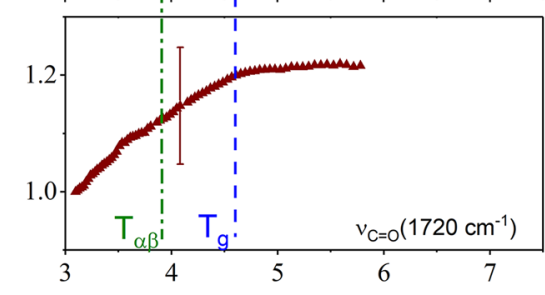

b)

$1000 / \mathrm{T}\left(\mathrm{K}^{-1}\right)$
FIG. 5. Comparison of inter- and intramolecular dynamic of PEGD in bulk. (a) Dynamic glass transition ( $\alpha$-relaxation) and the local $(\beta)$ processes and the shift of the selected absorption bands (stretching of COC: $v_{\mathrm{COC}}$, stretching of $\mathrm{CC}$ aromatic: $v_{\mathrm{CC}}$, stretching of $\mathrm{C}=\mathrm{O}$ : $\left.v_{\mathrm{C}=\mathrm{O}}\right) \Delta \bar{v}=\bar{v}-\bar{v}_{323 \mathrm{~K}}$ of PEGD with respect to the spectral position at $323 \mathrm{~K}$. (b) The dielectric strength $(\Delta \varepsilon)$ and the oscillator strength rescaled with respect to the value at $323 \mathrm{~K}$. The vertical dashed-dotted and dashed lines denote $\mathrm{T}_{\alpha \beta}$ and the calorimetrically determined $\mathrm{T}_{\mathrm{g}}$. The error bars are smaller than the symbols if not stated otherwise. for PEGEA than for PEGD. This is attributed to the significantly larger conformational transformations in PEGEA upon cooling, allowing larger changes in intra- and inter-molecular H-bonding, and therefore larger shifts. ${ }^{59,61}$

In summary, structural changes related to the dynamic glass transition can be clearly monitored by IR-spectroscopy. But also well above $\mathrm{T}_{\mathrm{g}}$, around the extrapolated merging temperature of the dielectric $\alpha$ and $\beta$ relaxation, changes in the IR-signature can be observed: in particular, the composition of gauche-conformers and trans-conformers changes between $\mathrm{T}_{\alpha \beta}$ and $\mathrm{T}_{\mathrm{g}}$ by about $10 \%$ in the case of PEGEA. Interestingly similar short chain ethylene glycols without phenyl end groups crystallize in the same temperature region. The detailed relation between the dielectrically active relaxations, conformation changes, and crystallization is to be unravelled in future work.

Figures 6 and 7 contrast the inter- and intra-molecular dynamics in bulk to data obtained for confined materials. This comparison allows us to draw the following qualitative conclusions: (i) For smaller pores, $\mathrm{T}_{\mathrm{g}}$ shifts to lower temperatures as commonly observed. ${ }^{31,36,62,63}$ This shift appears more pronounced in the kinks of the IR results than expected from 

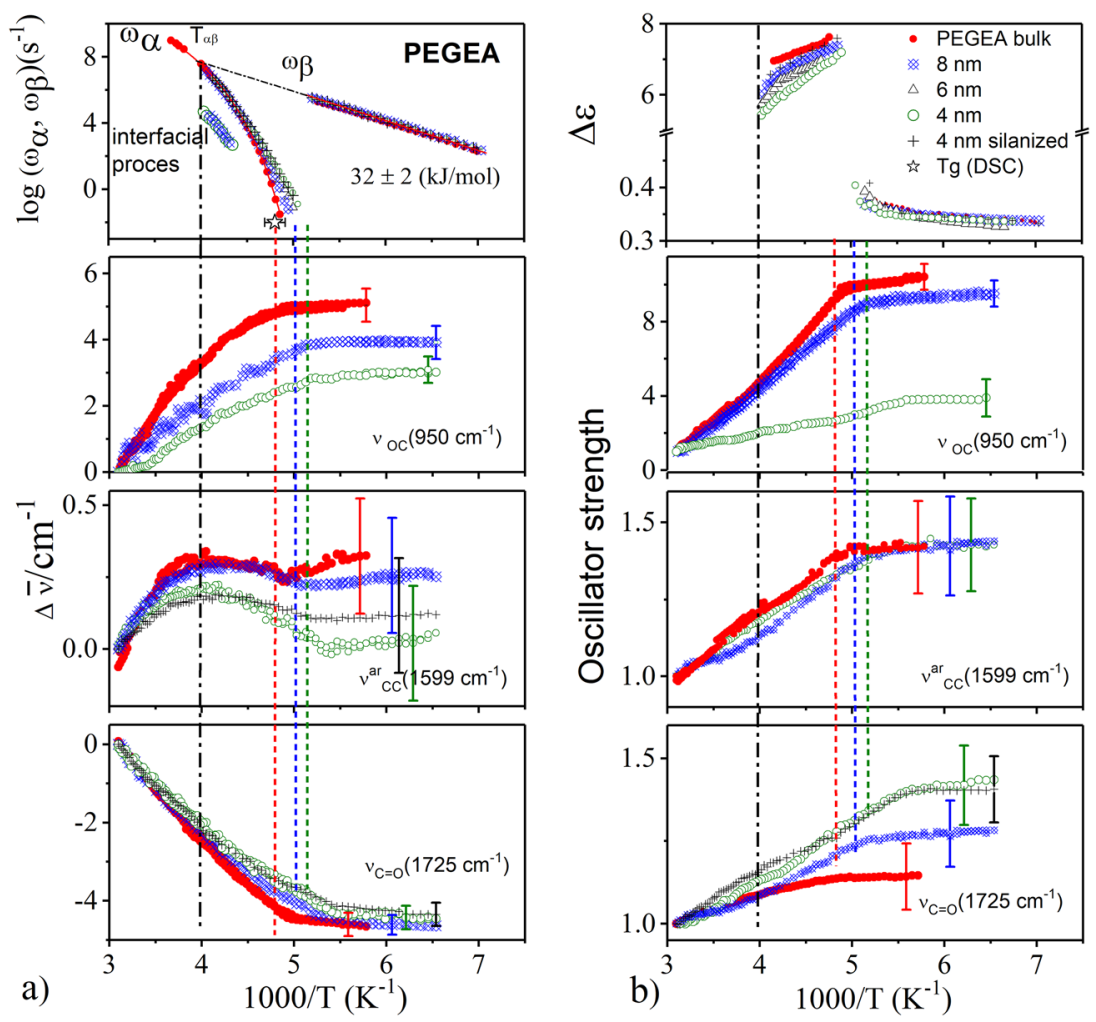

FIG. 6. Comparison of inter- and intramolecular dynamic of PEGEA in bulk and confined in nanopores of mean diameters of $4 \mathrm{~nm}, 6 \mathrm{~nm}$, and $8 \mathrm{~nm}$ : (a) Relaxation rates of the dynamic glass transition ( $\alpha$-relaxation) and the local $(\beta)$ processes and the shift of the absorption bands $\Delta \bar{v}=\bar{v}-\bar{v}_{323} \mathrm{~K}$ of PEGEA with respect to the spectral position at $323 \mathrm{~K}$. (b) The dielectric strength $(\Delta \varepsilon)$ and the oscillator strength rescaled with respect to the value at $323 \mathrm{~K}$. The error bars are smaller than the symbols if not stated otherwise.

the extrapolation of the dielectric $\alpha$-relaxation rates. Consequently, we expect the deviation of $\omega_{\alpha}$ from a VFT-dependence to increase close to $\mathrm{T}_{\mathrm{g}}$. (ii) Modes associated with the vibrations in $\mathrm{O}-\mathrm{CH}_{2}-\mathrm{CH}_{2}$ units $\left(\sim 938 \mathrm{~cm}^{-1}, \sim 950 \mathrm{~cm}^{-1}\right)$ are apparently blue shifted because of conformational changes of chains. Temperature dependencies of both the band shift and oscillator strength show an evident change of the slope at $\mathrm{T}_{\mathrm{g}}$. In nano-pores, the band shifts become less pronounced with decreasing pore size due to the reduced thermal expansion as also seen from $\omega_{\alpha}{ }^{36}$ and the increased stability of
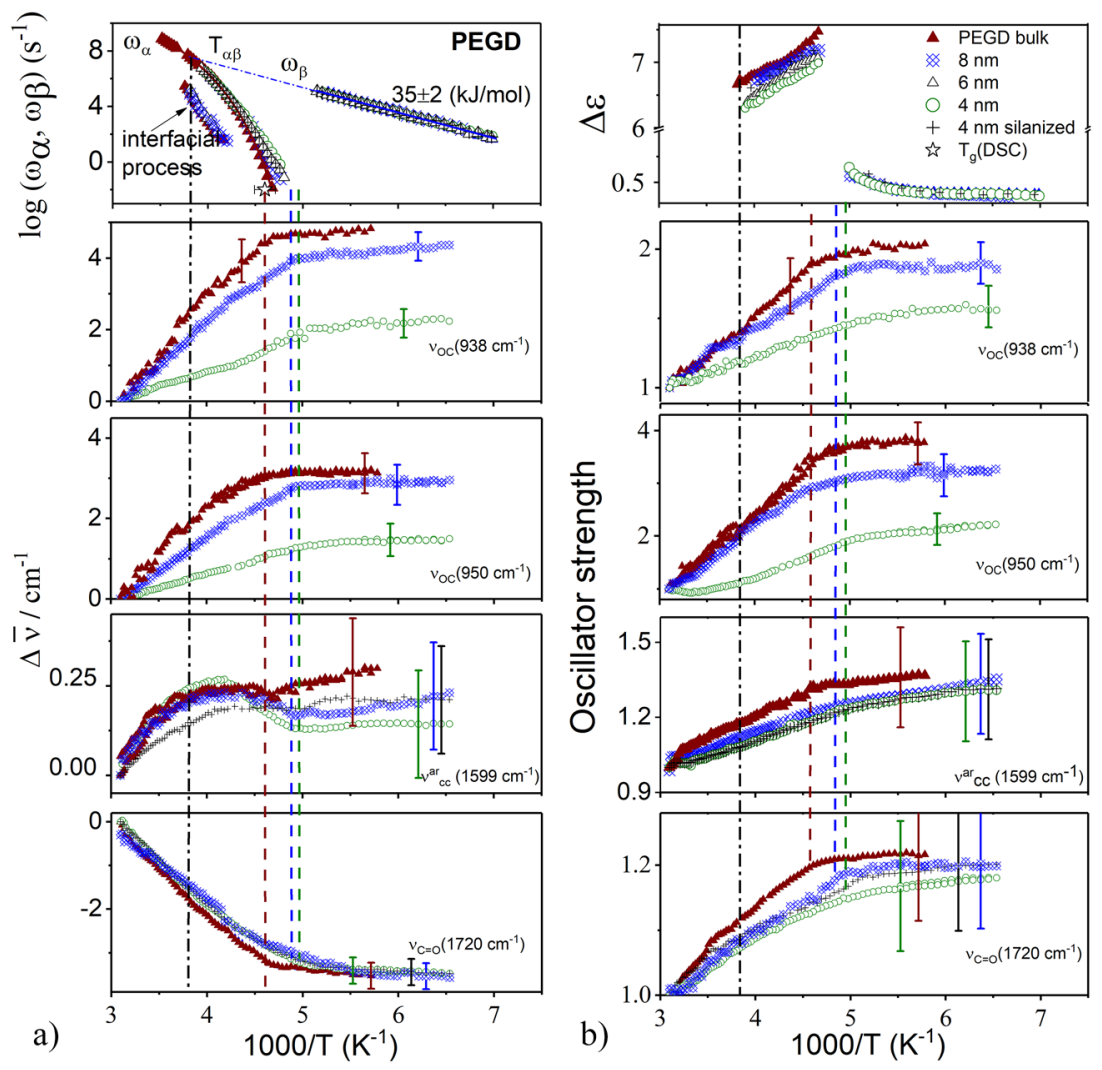

FIG. 7. Comparison of inter- and intramolecular dynamic of PEGD in bulk and confined nanopores of mean diameters of 4,6 , and $8 \mathrm{~nm}$ : (a) Dynamic glass transition ( $\alpha$-relaxation) and the local $(\beta)$ processes and the shift of the absorption bands $\Delta \bar{v}=\bar{v}-\bar{v}_{323 \mathrm{~K}}$ of PEGD with respect to the spectral position at $323 \mathrm{~K}$. (b) The dielectric strength $(\Delta \varepsilon)$ and the oscillator strength rescaled with respect to the value at $323 \mathrm{~K}$. The error bars are smaller than the symbols if not stated otherwise. 
TABLE I. Parameters of the VFT fits for the $\omega_{\alpha}$ process.

\begin{tabular}{lccccc}
\hline \hline Sample & $\omega_{\infty}\left(\mathrm{s}^{-1}\right)$ & $\mathrm{D}$ & $\mathrm{T}_{0}(\mathrm{~K})$ & $\mathrm{T}_{\mathrm{g}}(\mathrm{BDS})(\mathrm{K})$ & $\mathrm{T}_{\mathrm{g}}(\mathrm{DSC})(\mathrm{K})$ \\
\hline PEGEA & $3.4 \times 10^{12}$ & 3.8 & 185.2 & 206 & 209 \\
PEGD & $7.2 \times 10^{12}$ & 6.0 & 181.4 & 214 & 219 \\
\hline \hline
\end{tabular}

trans-conformers for smaller pore sizes. ${ }^{47,56}$ High-pressure FTIR studies of Poly(Methyl Methacrylate) (PMMA) ${ }^{64}$ revealed the significant volume dependence of the Grüneisen parameters (relating the shift of IR bands with the volume thermal expansion coefficient, material density, and heat capacity) of $\mathrm{C}-\mathrm{C}-\mathrm{O}$ stretching modes in the range $1100-1300 \mathrm{~cm}^{-1}$. This indicates that intramolecular vibrations experience the changes of inter-chain void spaces. This also supports our statement that intra-chain $\mathrm{C}-\mathrm{C}-\mathrm{O}$ vibrations are sensitive to increased free molecular volume under confinement. (iii) The ring stretching vibrations $\left(v^{\mathrm{ar}} \mathrm{CC}\right)$ show a more pronounced change of slopes at the temperature dependence of the band shift as the pore size decreases. (iv) The spectral shift of the $v_{\mathrm{C}=\mathrm{O}}$ mode as a function of temperature becomes more gradual with decreasing pore size because the nanoscale confinement reduces the local density changes ${ }^{36,65}$ For PEGD, the change in the oscillator strength shifts with $\mathrm{T}_{\mathrm{g}}$ of the different pore sizes, as it is the case for the aforementioned bands. However, for PEGEA, the situation is reversed, and a more marked increase in the oscillator strength as temperature decreases is found in nanopores than in bulk. This can be rationalized by the higher abundance of trans-conformers under confinement, allowing for more intermolecular polar interactions of $\mathrm{C}=\mathrm{O}$ groups and hence larger absorbance. ${ }^{66}$

In general, our proposed combined broadband dielectric spectroscopy and Fourier-transform infrared spectroscopy analysis reveals the significant role of inter/intra-molecular interactions during the vitrification process. This approach lets us to trace the glass transition on nanoscale confinement at the microscopic level. It demonstrates that spatial constraints influence intramolecular potentials as manifested by the higher presence of trans-conformers, increased sensitivity to the temperature of phenyl groups at the end of chains, and reduced the attractive polar interactions.

\section{CONCLUSIONS}

In summary, the interplay between inter- and intramolecular interactions in the course of glassy solidification for the case of two oligomer poly-ethylene-glycol derivatives PEGEA and PEGD is demonstrated for the bulk and under conditions of nanometric confinement. By analyzing the temperature dependence of specific IR absorption bands far above and below the calorimetric glass transition temperature $T_{g}$, the evolution of the intramolecular potentials of characteristic molecular moieties is unraveled and compared with the dynamic glass transition as measured with broadband dielectric spectroscopy. Specific features are observed at $T_{g}$ and the temperature $\mathrm{T}_{\alpha \beta}$ where the $\alpha$ - and the $\beta$-relaxation merge; (i) from the temperature dependencies of the band shift and oscillator strength of $v_{\mathrm{COC}}$ stretching vibration in the gauche-state, it is concluded that the process of conversion of a higher energy conformation (gauche) to a lower-energy one (trans) starts already above $T_{\alpha \beta}$ and levels off below $T_{g}$. (ii) For the band shift of $v^{\text {ar }}{ }_{\mathrm{CC}}$ and the oscillator strength of $v_{\mathrm{C}=\mathrm{O}}$, one finds a "kink" close to $\mathrm{T}_{\alpha \beta}$ and not only at $\mathrm{T}_{\mathrm{g}}$. This proves that the terminal groups are sensitive to the mentioned conformational changes. (iii) The influence of end groups is also reflected in the dominant role of gauche-conformation for PEGEA in contrast to PEGD, for which predominately trans-conformations are observed. (iv) Under conditions of confinement, transconformers are favoured limiting the likelihood to establish intramolecular H-bonds in the case of PEGEA. (v) For the first time, it is demonstrated that under confinement intramolecular properties are more sensitive to temperature than in bulk, an effect attributed to the reduced density in nanometric pores. The presented intricate details prove that glassy solidification has to be understood on a molecular scale beyond coarse grained descriptions.

\section{ACKNOWLEDGMENTS}

M.J.-D. acknowledges the National Science Centre (Grant No. SONATA11: UMO-2016/21/D/ST3/01299) for financial support as well as Dr. Beata Mossety-Leszczak for DSC measurements of the glass transition temperature for studied compounds at the Rzeszow University of Technology, Poland. W.K. and F.K. thank the German Science Foundation for financial support within the framework of CRC TRR 102. J.R.S. gratefully acknowledges the National Science Foundation for financial support through the Polymers Program Award No. DMR-1508394. We would like to thank Tyler Cosby from the Department of Chemical and Biomolecular Engineering at the University of Tennessee, Knoxville, for a thorough revision of the manuscript.

${ }^{1}$ L. Berthier and G. Biroli, Rev. Mod. Phys. 83, 587 (2011).

${ }^{2}$ A. Cavagna, Phys. Rep. 476, 51 (2009).

${ }^{3}$ N. Jadhav, V. Gaikwad, K. Nair, and H. Kadam, Asian J. Pharm. 3, 82 (2009).

${ }^{4}$ Y. H. Roos, Annu. Rev. Food Sci. Technol. 1, 469 (2010).

${ }^{5}$ S. R. Forrest and M. E. Thompson, Chem. Rev. 107(4), 923 (2007).

${ }^{6}$ P. G. Debenedetti and F. H. Stillinger, Nature 410, 259 (2001).

${ }^{7}$ E.-J. Donth, The Glass Transition (Springer Berlin Heidelberg, Berlin, Heidelberg, 2001).

${ }^{8}$ Broadband Dielectric Spectroscopy, edited by F. Kremer and A. Schonhals (Springer-Verlag Berlin Heidelberg GmbH, 2003).

${ }^{9}$ C. A. Angell, Science 267, 1924 (1995).

${ }^{10}$ W. Xu, M. T. Sandor, Y. Yu, H.-B. Ke, H.-P. Zhang, M.-Z. Li, W.-H. Wang, L. Liu, and Y. Wu, Nat. Commun. 6, 7696 (2015).

${ }^{11}$ J. W. P. Gutzow and I. S. Schmelzer, The Vitreous State, 2nd ed. (Springer Berlin Heidelberg, New York, Dordrecht, London, 1995).

${ }^{12}$ A. L. Greer, Science 267, 1947 (1995).

${ }^{13}$ M. D. Ediger, C. A. Angell, and S. R. Nagel, J. Phys. Chem. 100, 13200 (1996).

${ }^{14}$ P. Lunkenheimer, U. Schneider, R. Brand, and A. Loid, Contemp. Phys. 41, 15 (2000).

${ }^{15}$ G. P. Johari and M. Goldstein, J. Chem. Phys. 53, 2372 (1970).

${ }^{16}$ M. Paluch, C. M. Roland, S. Pawlus, J. Zioło, and K. L. Ngai, Phys. Rev. Lett. 91, 115701 (2003).

${ }^{17}$ R. Böhmer, G. Diezemann, B. Geil, G. Hinze, A. Nowaczyk, and M. Winterlich, Phys. Rev. Lett. 97, 135701 (2006).

${ }^{18}$ C. M. Roland, S. Hensel-Bielowka, M. Paluch, and R. Casalini, Rep. Prog. Phys. 68, 1405 (2005)

${ }^{19}$ A. Kudlik, S. Benkhof, T. Blochowicz, C. Tschirwitz, and E. Rössler, J. Mol. Struct. 479, 201 (1999).

${ }^{20}$ K. L. Ngai and M. Paluch, J. Chem. Phys. 120, 857 (2004). 
${ }^{21}$ M. Mierzwa, S. Pawlus, M. Paluch, E. Kaminska, and K. L. Ngai, J. Chem. Phys. 128, 044512 (2008).

${ }^{22}$ G. Adam and J. H. Gibbs, J. Chem. Phys. 43, 139 (1965).

${ }^{23}$ J. C. Dyre, T. Hechsher, and K. Niss, J. Non-Cryst. Solids 355, 624 (2009).

${ }^{24}$ S. Das, Rev. Mod. Phys. 76, 785 (2004).

${ }^{25} \mathrm{G}$. S. Grest and M. H. Cohen, "Liquids, glasses, and the glass transition: A free-volume approach," in Advances in Chemical Physics, edited by I. Prigogine and S. A. Rice (John Wiley \& Sons, Inc., 2007), Vol. 48.

${ }^{26}$ J. C. Dyre, Rev. Mod. Phys. 78, 953 (2006).

${ }^{27}$ V. Lubchenko and P. G. Wolynes, Annu. Rev. Phys. Chem. 58, 235 (2007).

${ }^{28}$ I. Bahar, B. Erman, G. Fytas, and W. Steffen, Macromolecules 27, 5200 (1994).

${ }^{29}$ W. K. Kipnusu, W. Kossack, C. Iacob, P. Zeigermann, M. Jasiurkowska, J. R. Sangoro, R. Valiullin, and F. Kremer, Soft Matter 9, 4681 (2013).

${ }^{30}$ P. Papadopoulos, W. Kossack, and F. Kremer, Soft Matter 9, 1600 (2013).

${ }^{31}$ W. K. Kipnusu, W. Kossack, C. Iacob, M. Jasiurkowska, J. Rume Sangoro, and F. Kremer, Z. Phys. Chem. 226, 797 (2012).

${ }^{32}$ M. Jasiurkowska, W. Kossack, R. Ene, C. Iacob, W. K. Kipnusu, P. Papadopoulos, J. R. Sangoro, M. Massalska-Arodź, and F. Kremer, Soft Matter 8, 5194 (2012)

${ }^{33}$ W. Kossack, K. Adrjanowicz, M. Tarnacka, W. K. Kipnusu, M. Dulski, E. U. Mapesa, K. Kaminski, S. Pawlus, M. Paluch, and F. Kremer, Phys. Chem. Chem. Phys. 15, 20641 (2013).

${ }^{34}$ K. Adrjanowicz, K. Kaminski, M. Dulski, M. Jasiurkowska-Delaporte, K. Kolodziejczyk, M. Jarek, G. Bartkowiak, L. Hawelek, S. Jurga, and M. Paluch, Macromolecules 47, 5798 (2014).

${ }^{35}$ M. Tress, E. U. Mapesa, W. Kossack, W. K. Kipnusu, M. Reiche, and F. Kremer, Science 341, 1371 (2013).

${ }^{36}$ W. K. Kipnusu, M. Elsayed, W. Kossack, S. Pawlus, K. Adrjanowicz, M. Tress, E. U. Mapesa, R. Krause-Rehberg, K. Kaminski, and F. Kremer, J. Phys. Chem. Lett. 6, 3708 (2015).

${ }^{37}$ W. K. Kipnusu, M. Elsayed, R. Krause-Rehberg, and F. Kremer, J. Chem. Phys. 146, 203302 (2017)

${ }^{38}$ K. Adrjanowicz, K. Kaminski, K. Koperwas, and M. Paluch, Phys. Rev. Lett. 115, 265702 (2015).

${ }^{39}$ K. Adrjanowicz, K. Kaminski, M. Tarnacka, K. Szutkowski, L. Popenda, G. B. Bartkowiak, and M. Paluch, Phys. Chem. Chem. Phys. 18, 10585 (2016).

${ }^{40}$ S. Alexandris, P. Papadopoulos, G. Sakellariou, M. Steinhart, H. J. Butt, and G. Floudas, Macromolecules 49, 7400 (2016)

${ }^{41}$ C. Iacob, J. R. Sangoro, P. Papadopoulos, T. Schubert, S. Naumov, R. Valiullin, J. Kärger, and F. Kremer, Phys. Chem. Chem. Phys. 12, 13798 (2010).
${ }^{42}$ C. Iacob, J. R. Sangoro, W. K. Kipnusu, R. Valiullin, J. Kärger, and F. Kremer, Soft Matter 8, 289 (2012).

${ }^{43}$ Fourier Transform Infrared Spectrometry, edited by P. R. Griffiths and J. A. De Haseth, 2nd ed. (John Wiley \& Sons, Inc., 2007).

${ }^{44}$ B. Valeur, Molecular Fluorescence: Principles and Applications (WileyVCH Verlag GmbH, 2001).

${ }^{45}$ T. Miyazawa, Y. Ideguchi, and K. Fukushima, J. Polym. Sci. 62, S146 (1962).

${ }^{46}$ T. Miyazawa, K. Fukushima, and Y. Ideguchi, J. Chem. Phys. 37, 2764 (1962).

${ }^{47}$ R.-S. Luo and J. Jonas, J. Raman Spectrosc. 32, 975 (2001).

${ }^{48}$ M. Rozenberg, A. Loewenschuss, and Y. Marcus, Spectrochim. Acta, Part A 54, 1819 (1998).

${ }^{49}$ J. M. O'Reilly and R. A. Mosher, Macromolecules 14, 602 (1981).

${ }^{50}$ O. N. Tretinnikov and K. Ohta, Macromolecules 35, 7343 (2002).

${ }^{51}$ R. Begum and H. Matsuura, J. Chem. Soc., Faraday Trans. 93, 3839 (1997).

${ }^{52}$ S. A. Wahab and H. Matsuura, Phys. Chem. Chem. Phys. 3, 4689 (2001).

${ }^{53}$ H. Matsuura and K. Fukuhara, J. Polym. Sci., Part B: Polym. Phys. 24, 1383 (1986).

${ }^{54} \mathrm{G}$. Socrates, Infrared and Raman Characteristic Group Frequencies. Tables and Charts, 3rd ed. (John Wiley \& Sons, 2001).

${ }^{55}$ M. Tarnacka, E. Kaminska, K. Kaminski, C. M. Roland, and M. Paluch, J. Phys. Chem. C 120, 7373 (2016).

${ }^{56}$ T. S. Gulmen and W. H. Thompson, Langmuir 22, 10919 (2006).

${ }^{57}$ T.-S. Kim and R. H. Dauskardt, Nano Lett. 10, 1955 (2010).

${ }^{58}$ F. Barroso-Bujans, S. Cerveny, Á. Alegría, and J. Colmenero, Macromolecules 46, 7932 (2013).

${ }^{59}$ G. R. Desiraju and T. Steiner, The Weak Hydrogen Bond in Structural Chemistry and Biology (Oxford University Press, New York, 1999).

${ }^{60}$ M. Brogly, S. Bistac, and J. Schultz, Macromolecules 31, 3967 (1998).

${ }^{61}$ T. Steiner, Chem. Commun. 0, 727 (1997).

${ }^{62}$ W. K. Kipnusu, M. M. Elmahdy, E. U. Mapesa, J. Zhang, W. Böhlmann, D.M. Smilgies, C. M. Papadakis, and F. Kremer, ACS Appl. Mater. Interfaces 7, 12328 (2015).

${ }^{63}$ C. Alba-Simionesco, B. Coasne, G. Dosseh, G. Dudziak, K. E. Gubbins, R. Radhakrishnan, and M. Sliwinska-Bartkowiak, J. Phys. Condens. Matter 18, R15 (2006).

${ }^{64}$ E. D. Emmons, R. G. Kraus, S. S. Duvvuri, J. S. Thompson, and A. M. Covington, J. Polym. Sci., Part B: Polym. Phys. 45, 358 (2007).

${ }^{65}$ D. Kilburn, P. E. Sokol, V. García Sakai, and M. Ashraf Alam, Appl. Phys. Lett. 92, 033109 (2008)

${ }^{66}$ A. V. Iogansen, Spectrochim. Acta, Part A 55, 1585 (1999). 